\title{
Public Field and Self-Existence: The Integration and Deviation of Young People in Small Towns Under the New Cultural Business
}

\author{
Fan Zhou $^{1,2 \mathrm{a}}$ Luo Mengke $\mathrm{b}^{1 \mathrm{*} *}$ \\ ${ }^{1}$ School of Culture and Creativity, Hangzhou Normal University, Yuhang District, Hangzhou, Zhejiang, China \\ ${ }^{2}$ School of Cultural Industry Management, Communication University of China, Chaoyang District, Beijing, China \\ afanzhou94@163.com \\ b*15840399409@163.com
}

\begin{abstract}
Through oral history interviews with 10 young people in small towns, the public field theory is used to study the cultural and social integration of young people in small towns in developed commercial cities under the new cultural business conditions. The study found that the social integration of young people in small towns deviated. In the field of participation, the habituation of small cities affects the behavioral choices of young people in small towns, and cannot be applied to the rules of urban public life; in the field of culture, the obstacles in the process of cultural integration and the "drive away" shown by the city itself; In the field of communication, the young people in small towns have a clear coexistence of reality mapping, focusing on the opposition between traditional and modern ways of thinking. The specific manifestations are: public opinion suppresses people, "face" is valuable, and social capital can be accumulated.
\end{abstract}

Keywords: Young people in small towns, new cultural formats, field theory, social integration

\section{STATEMENT OF PROBLEM}

Young people in small towns in China grew up with the wave of reform and opening up. Their hometowns completed the modern process of urbanization earlier. As a cultural symbol, the "small town youth" is constantly being lifted up in the dust under the great wheel of time, revealing the label of renovation, completing the confrontation and collision of the times with a distinctive characteristic. From the slightly mocking "image of the other" and "self-deprecating" to the "plain personality" of successful people, young people in small towns are no longer confined to the young people born and grown up in the "small town" defined by the division of administrative regions. But a kind of identity and identity imagination.

The "Proposals of the Central Committee of the Communist Party of China on Formulating the Fourteenth Five-Year Plan for National Economic and Social Development and Long-Term Goals for 2035", which was reviewed and approved by the Fifth Plenary Session of the 19th Central Committee, is really related to the thinking of cultural system reconstruction. At the same time, the development of new cultural business forms is strong. New cultural business forms represented by new media, live broadcast, short video, VR, AI, online education, etc. have become an important force leading and demonstrating the development of cultural industries. Young people in small towns are in among them, what kind of changes have been experienced? In the process of urbanization, how are the social integration and social performance of young people in small towns? What role do small-town youths play in urbanization and backfeeding the countryside under the new cultural industry? Based on this, this article attempts to use the theory of public field to analyze the status quo of young people in small towns in the new cultural industry and their social integration in the process of urbanization. It analyzes the success of young people in small towns from the field of participation, cultural field and communication field. And troubles, gains and deviations, and try to explore the causes of this phenomenon, so as to accumulate strength in the process of urbanization and even feeding the countryside. 


\section{RESEARCH THEORY LITERATURE REVIEW}

\subsection{Portrayal of Group Portraits of Young People in Small Towns}

There is no unified concept of young people in small towns abroad. Research on youths from small towns generally focuses on the social integration of immigrant youths and the psychological characteristics of marginalized youths. For example, Silver, A, based on ethnological surveys, believes that when young Latino born in small towns immigrate to a new destination, even if the social capital of the small town creates opportunities for them, youths born in small towns are still keen. Realize that they are excluded from legal and social integration ${ }^{[1]}$. Brown $\mathrm{T}$ and others conducted interviews and ethnographic field trips in the town of "Dajeling" in West Bengal. They believe that the youth in this region are in terms of obtaining middle-class jobs, modern education, and lifestyles related to neoliberal globalization. At a disadvantage, they expressed a strong desire for "exposure", and this kind of "exposure" can only be satisfied by emigration, especially to the Indian metropolis. However, they are frustrated with the desire to emigrate because they feel restricted by the traditional family structure, discrimination in big cities, and the uneven time between regional towns and "Global India" [2]. Paceley, $\mathrm{M}$ et al. used qualitative interviews and online surveys to study the relationship between size, community harmony, and specific resources for transgender youth in third- and fourth-tier cities and county-level regions. Studies have shown that transgender youth in small towns may face more stigma and lack of social resources ${ }^{[3]}$.

The domestic concept of young people in small towns has moved from a single to multiple, from a simple administrative division to a complex multi-level structure and has experienced the evolution from "movie groups""cultural consumer groups"-"social class groups". Zhang Yiwu first proposed the concept of "small town youth", pointing out that "small town youth" refers to a new concept proposed by the industry to audiences in the Chinese film market, specifically referring to third- and fourth-tier cities as the center, "post-80s" and "post-90s" young people Chinese movie audience ${ }^{[4]}$. From 2015 to 2017, academic research on "small town youth" focused on the "movie consumer group" and conducted in-depth discussions from the sinking of the movie market and the representation of small town youth in film and television works. In 2017, Hong Zexin divided the young people in small towns from the perspective of cultural consumption. He pointed out that young people in small towns live in county-level cities, are engaged in traditional industries, and are between 15-34 years old, and their disposable income is increasing year by year, but their spiritual life is relatively scarce. Youth groups ${ }^{[5]}$. Lu Dewen defined the young people in small towns from the perspective of social stratification and distinguished them from "rural youth" and "urban white-collar workers". It is believed that the "small town youth" class is mainly composed of two groups of people: one is the professional youth who have struggled for a period of time in a big city (whether studying or working) and have accumulated a certain amount of capital, but have not established a foothold in the big city; the other is the family The conditions are relatively good, and the rural youth who successfully settled in the city ${ }^{[6]}$. Wang Yuling believes that young people in small towns generally refer to youth groups from third-, fourth-tier cities and below, including those who were born in third-, fourth-tier cities and below, and now live in first- and second-tier cities ${ }^{[7]}$.

In summary, scholars define youth in small towns based on two aspects: First, starting from the division of administrative regions, that is, youth in fourth- and fifthtier cities, counties, and organizational towns. The second is divided from the perspective of life belonging, that is, professional youth who earn a living in big cities or rural youth who settle in cities. This article combines scholars' viewpoints and based on research topics and defines small-town youths as professional youths who were born in third- and fourth-tier cities and below counties, organized towns, work and live in large cities.

\subsection{The Public Space and Presentation Form of the Field}

The term "field" and "public sphere" are derived from the English "public sphere". In Chinese publications, public sphere is also translated as "public domain". The public sphere of the bourgeoisie was initially developed in the field of literature and art, and later became a public sphere that has a direct impact on political issues ${ }^{[8]}$. Although the bourgeois public sphere is open to all private persons in principle, in practice, the public sphere is made up of the public with reading ability among the bourgeoisie in the 18th century. As the masses of cultural criticism turn to the masses of cultural consumption, the public is divided. Become a few experts and publicly accepted consumers without publicly critical consciousness. Therefore, the "public field" that Habermas considers refers to the dissemination of public opinion in public space, and the public space for discussion of events formed by popular reading in newspapers and media. From the 18th century to the present, in the development of the "public field" theory, the media and public opinion have formed an intimate and interactive relationship. Bourdieu believes that "field" is inseparable from "relationships" and "networks." In dense and complex social relationships, people tend to manage self-behavior to reach a certain consensus, thus forming field awareness. That is, the mutual connection and confrontation of various forces ${ }^{[9]}$. Kafka believes that the field not only refers to the 
physical environment, but also includes the behavior of others and many factors connected to it. Therefore, every human behavior is affected by the field in which the action occurs ${ }^{[10]}$.

From the perspective of new cultural formats, Internet platforms (Internet + ) and cultural and entertainment services occupy an important proportion of daily cultural consumption. Some new formats have become "hidden champions" in daily cultural consumption for post-90s and post-00s ${ }^{[11]}$. Based on this, the public field in this article refers to the Internet platform for cultural and entertainment consumption by young people in small towns and the interactive space derived from it.

\subsection{Research Focus on Social Inclusion}

Domestic scholars' research on "social integration" mainly focuses on: the ideological integration of socialist core values ${ }^{[12-14]}$, the urban integration and social exclusion of migrant workers and the new generation of migrant workers ${ }^{[15-16]}$, and the social integration of migrant children, Human capital transformation in psychological integration and social integration ${ }^{[17-18]}$, etc. Xiao Baoyu, Zhu Yu, etc. constructed an index system for the comparison of integration and isolation, and analyzed the status of the migrant population's subjective social integration and influencing factors through the measurement of the degree of subjective social integration, and analyzed the migration model, livelihood capital, social network, and institutional policies. Verify the results from an equal angle ${ }^{[19]}$. Peng Dasong used factor analysis and OLS model to analyze the influencing factors of the urban integration of the elderly floating population and believed that the urban integration of the elderly floating population is composed of three dimensions: cultural integration, psychological identification and interaction ${ }^{[20]}$. Ni Liangxin and $\mathrm{Ou}$ Shutong built a triple logic from the integration of socialist core values into targeted poverty alleviation, and believed that the socialist core values are conducive to the realization of targeted poverty alleviation from the three aspects of theoretical logic, value logic and action logic ${ }^{[21]}$. Zhang Kankan and Xue Rui used Xuxi Community in Taiyuan City as an example ${ }^{[22]}$ to study from the perspective of the social adaptability of the floating population in villages in the city. They believe that the social adaptability of the floating population is mainly divided into three aspects: economic adaptability and life. Adaptability and adaptability of interpersonal relationship, and make countermeasures and suggestions from the aspects of urban living space quality and urban resources.

According to the literature review, this study combines the three aspects of the field of participation, cultural field, and communication field of public field theory, from the understanding and participation of social public policies, the degree of adaptation to urban rules, the scope of social communication, and the scope of social communication. Frequency, etc. design and analyze the results of the integration and deviation of young people in small towns under the new cultural business format.

\section{RESEARCH DESIGN}

This research adopts the research method of oral history. According to the definition of "small town youth" in this article, the semi-structured interview method is used to interview professional youths who were born in third- and fourth-tier cities and below counties, organizational towns, and work and live in large cities. . Draw up some guiding questions and outlines in advance so that you can clarify the direction in the actual interview. The interview questions centered on the problems between young people in small towns and social integration, including demographic factors such as gender, occupation, age, and work, the degree of understanding and participation in social public policies, the degree of adaptation to urban rules, and the level of social interaction. Range and frequency, frequency and reason of job replacement, etc. The collection of interview data is mainly through recording and transcribing text. A total of 10 interviewees, young people from small towns from different cities, different education backgrounds and different genders, are representative. A single interview time is about 13 minutes. A total of 2 hours of recording files are recovered and the recordings are transcribed into text. , Transcribed about 8000 words of valid text. These qualitative data will supplement the quantitative research. Due to limited space, this article uses 6 interviewers' cases.

Table 1. Summary of interviewees

\begin{tabular}{c|c|c|c|c|c|c|c}
\hline No. & Gender & Age & Education & Hometown & $\begin{array}{c}\text { Working } \\
\text { City }\end{array}$ & $\begin{array}{c}\text { Working } \\
\text { Years }\end{array}$ & Working Situation \\
\hline 1 & $\mathrm{~F}$ & 25 & Bachelor & Changzhi & Beijing & 3 & Exhibition company salesperson \\
\hline 2 & $\mathrm{~F}$ & 25 & Bachelor & Hebi & Shanghai & 1 & Research Institute Assistant \\
\hline 3 & $\mathrm{M}$ & 25 & Junior & Luoyang & Hangzhou & 3 & courier delivery person \\
\hline 4 & $\mathrm{M}$ & 28 & Undergraduate & Quzhou & Hangzhou & 3 & Ali programmer \\
\hline 5 & $\mathrm{M}$ & 26 & Undergraduate & Shangrao & Shenzhen & 3 & takeaway delivery worker \\
\hline 6 & $\mathrm{~F}$ & 25 & Junior & Anji & Tianjin & 3 & manicurist \\
\hline
\end{tabular}




\begin{tabular}{c|c|c|c|c|c|c|c}
\hline 7 & $\mathrm{M}$ & 25 & Postgraduates & Yuzhou & Beijing & 1 & enterprise employees \\
\hline 8 & $\mathrm{M}$ & 23 & Junior & Yueyang & Changsha & 2 & Barber \\
\hline 9 & $\mathrm{~F}$ & 27 & Undergraduate & Shangqiu & Zhengzhou & 2 & kindergarten teacher \\
\hline 10 & $\mathrm{~F}$ & 28 & Undergraduate & Yucheng & Yantai & 3 & doctor \\
\hline
\end{tabular}

\section{RESULTS AND ANALYSIS}

\subsection{Participation in the Field: Strong Self- Expression and Unfamiliar Public Participation}

The field of participation in this article refers to the public expression of young people in small towns in the public domain (especially in public cyberspace), and their participation in community public services and community public affairs after they have separated from their original environment and integrated into the big city. Whether in the urban market domain or the rural domain, there exists the contest of rights and the interaction of relations between members of the society, in order to complete their behavior or practice. After being separated from the original environment and integrated into the big city, young people in small towns still retain the laws of human relations in the original environment, because habituation is a kind of ability that exists in the human temperament system, and it is difficult to change temporarily. The habituation of small cities affects because of the behavioral choices of young people in small towns, it is impossible to apply them to the rules of public life in the city.

Interviewer (No.9) whose hometown is in a county seat of Shangqiu jurisdiction, currently works as a kindergarten teacher in Zhengzhou. The university majored in pre-school education. After graduation, he followed his boyfriend to develop in his provincial capital Zhengzhou.

"I am going to get married with my boyfriend, and the family has prepared a wedding room. We bought secondhand houses in an old community. There are more elderly people in the community, and we don't usually communicate with other people in the community. Work in the kindergarten is relatively easy. When I'm not busy, I just stay at home and watch movies, or go out shopping. Since talking on Weibo and being scolded by some celebrity fans, he rarely expresses opinions on the Internet. They are all types of stealth surfing and eating melons. I usually shoot kindergarten life into Tiktok, and I have received a lot of likes, especially many mothers, who love to communicate with me and bring their baby's experience, but we also communicate online and never meet in private. It feels embarrassing to meet each other".

In the process of moving upwards and trying to integrate into the big city, the desire of expression of young people in small towns increases with the enhancement of their subjective consciousness. According to the "2019 Small Town Youth Report" released by Kwai in conjunction with "China Youth Daily", Sequoia China and Shence data, there are more than 230 million small town youths active in Kwai. In the past year, they have published more than 2.8 billion short videos on Kwai, with more than 2.6 billion views of the video, more than 80 billion likes, and more than 18 billion comments.

The interviewer (No.3) whose hometown was in Luoyang stayed in Hangzhou after graduating from junior college, working from a salesperson to real estate sales, and finally switched to a courier service. Currently living in a rented house in Yu hang District.

"I think Hangzhou is already very good, giving us a lot of convenience for outsiders. However, I rented a resettlement housing community. The community was full of Hangzhou natives. I couldn't understand what they said, so I didn't communicate much. My parents are not here, and I still think this is not my home, maybe because I didn't buy a house. I am quite comfortable with Hangzhou, but I still don't feel that I am a Hangzhou native without a house."

The positive feedback from young people in the small town reflected the fact that the chassis and ceiling were too low. For young people in small towns struggling in big cities, "houses", "native families", and "settlement" are their own essential ceilings, which together constitute the rising bottleneck of youth. Reflected in the field of participation in the public space, young people in small towns cannot escape the limitations of their own class. They focus more on the "home courtyard" and lack the attention and thinking of "people from afar", which to a certain extent reflects the deviations from mainstream values and public events.

\subsection{Cultural Field: Cultural Integration and Invisible Rejection}

After entering the city, young people in small towns cannot quickly adapt to the reinforced concrete-like daily life and rapidly changing interpersonal relationships. Cultural activities in urban communities are basically sponsored by community committees, and community residents participate in them as they wish. The cultural field of young people in small towns is obviously not in the community, but more concentrated on corporate culture and public cultural activities held in the city 
where they live. At present, many companies have actively devoted themselves to the enthusiasm of corporate culture construction, but the practices of some companies still remain in the text and concepts and cannot really land ${ }^{[23]}$. Therefore, whether it is the cultural field of the community or the cultural field of the enterprise, in the process of the young people in the small town as the "integrators" of the big city, the manager must consider not only the increase of economic income, the expansion of horizons, and the experience to accumulate, one should also consider the obstacles in the process of cultural integration and the "drive away" shown by the city itself.

The interviewer (No.1) whose hometown is in Changzhi is currently working as a salesperson in a convention and exhibition company in Beijing and is expected to be promoted to project manager this year. She has been doing an internship in Beijing since she graduated. In the three years from internship to work, she has not changed companies or jobs, and she still lives with her university roommate.

"I have a very good relationship with my colleagues in the company. But the nature of our work, the work mobility among colleagues is particularly high, many colleagues left after staying for less than a year, so there was no time to cultivate relationships. Personally, I also deliberately keep a distance from my colleagues. After all, they are not college classmates who know the bottom line. Many people are not sincere to you, and there is still a competitive relationship in the project. The company has also organized team building activities, but the effect is not very good. Leaders regard team building as part of their work, and employees treat team building as a holiday, and no one can communicate sincerely."

The interviewer (No.2) whose hometown is in Hebi is currently working as a research assistant at the Shanghai Institute of Science. She has worked for one year. His sister in his hometown has married and settled in Shanghai.

"I studied as a graduate student in Shanghai and stayed in Shanghai smoothly after graduation. The Shanghai Institute of Science is a relatively stable job with low mobility. Most of the colleagues are masters and doctors, and the working atmosphere and working environment are relatively simple. But most of my colleagues around are Shanghainese, life is relatively leisurely, I come from a small city, there will always be gaps in integrating with them. I don't work a lot of overtime. I basically use my phone or video with my friends on weekends. I rarely go to libraries or museums. On the one hand, I am tired from work, and on the other hand, traffic consumes too much time. The institute and other institutes have organized a lot of blind date events, and have participated in it several times, but the first thing the boys choose is whether their home is in Shanghai, and the boys who chat online are not at ease to meet each other."

According to the content of the interviews, there are cultural integration and invisible exclusion problems in the process of integration of young people in small towns into big cities. The specific manifestations are: the difference between rural culture and urban culture, the difference between modern corporate culture and school culture and family culture, urban Public cultural construction is not in place, etc. The relationship between "habituation" and culture proposed by Bourdieu: Culture and field are the relationship of mutual influence and restriction. Simply put, different cultures shape different fields, and different fields construct different cultures. The public space provided by the Internet did not enable young people in small towns to establish a new cultural field, and the broken field could not be repaired in the city, which reduced the sense of belonging of the integrators and eventually split into different individuals.

\subsection{Communication Field: Tradition and Modernity are Intertwined}

Bourdieu's "field and habituation" theory believes that since actors in the social field have the same status in this field affect their habituation, groups have similar personalities. Even a unified logic of action. This homogenous habit makes people establish close alliances, and similar contacts gradually rationalize their habit. Big cities impact the concept of young people in small towns, but many of the original characteristics are imprinted by the heavy soil. Therefore, young people in small towns have an obvious coexistence of reality mapping, focusing on the opposition between traditional and modern ways of thinking.

The interviewer (No.7) whose hometown was in Yuzhou worked in a state-owned enterprise in Beijing after graduating from graduate school.

"I studied both undergraduate and graduate students in Beijing. It has been nearly 9 years after working hours, but I am still very unfamiliar with this city. When I was in college, I was busy with my studies, except for some of the more famous scenic spots in Beijing, I haven't been to other places. When choosing a job, I also have a good stable job in the capital city of my hometown. But everyone in my family feels that working in Beijing is more worthy, so I chose to stay in Beijing. Although the current unit promises to solve the hukou problem, there are a lot of colleagues ahead of me, and my family is unable to help me pay down payment in Beijing. I want to leave Beijing but I am afraid that the low will not make the high."

The specific manifestations are public opinion suppresses people, "face" is valuable, and social capital can be accumulated. "Public opinion suppresses people", such as attention to public events, young people in small 
towns consciously or unconsciously, consciously and unconsciously, short-term or long-term postures of group and warmth. "Face" is valuable, and the modern consumption concept impacts the traditional concept of "savings". According to the data from the "2019 China Small Town Youth Development White Paper" jointly released by Paipaidai and Southern Weekend, the consumption of youth in small towns sexual expenditure accounts for nearly $40 \%$ of wages. Although the income of first- and second-tier youths is higher than that of third- and fourth-tier youths, they spend more. "Social capital can be accumulated." On the one hand, according to a survey of young people in small towns by Southern Weekend in 2018, young people in small towns love challenges and look forward to the future. Nearly $90 \%$ of them hope that their jobs will be challenging, and 58.2\% of people will overcome difficulties and work hard, I believe that we can achieve wealth accumulation through our own efforts. On the other hand, young people in small towns believe in human society and have a relatively high degree of acceptance of unfair treatment and unspoken rules.

\section{CONCLUSION}

Young people in small towns have obvious characteristics of urbanization, but they can't get rid of the stigma of towns and mud. The deviation in the social integration of young people in small towns is affected by many factors. First, in the field of participation, there is a contradiction between the defamiliarization of public participation and strong personal expression under the new cultural business format. Second, in the cultural field, there are cultural integration and invisible rejection in the process of small town youths integrating into the city. Third, in the field of communication, there is a collision and tear between traditional thinking and modern social rules.

According to the research conclusions, this research proposes suggestions for the social integration and cultural integration of young people in small towns in the new cultural business: First, city managers should build a complete social support system for young people in small towns to integrate into the city as soon as possible and improve urban rules. Second, strengthen the construction of social public culture, enrich the cultural ecology, and make the city's "cultural forest" lush. Grasp the trend of new cultural formats, use social media such as Douyin and Weibo to increase the threshold of public cultural influence, and actively explore the public online cultural space. And in a more modern and tolerant way, it is compatible and involved in art exhibitions, creative design and other cultural industries to attract the cultural integration of young people in small towns. Finally, young people in small towns should find a balance between traditional thinking and modern social rules. Abandon the dross in traditional thinking, actively embrace the healthy social rules and systems of modern civilization and find self-existence in the public domain in the interweaving and confrontation between tradition and modernity.

In the process of the country's vigorous implementation of urbanization, young people in small towns are an important part, representing the transformation of small town culture and the expansion of urban civilization. Studying young people in small towns can on the one hand alleviate social conflicts and promote urbanization, on the other hand, it can also accumulate strength for them in the process of urbanization and even feeding back the countryside.

\section{ACKNOWLEDGMENT}

Thanks to Professor Chen Xianyong, School of tourism management, Shenyang Normal University, for his amendment opinions, and thanks for the support of the project "Research on performance evaluation and influencing factors of cultural industry in Zhejiang Province" (Y202044864) from Zhejiang Provincial Department of education.

\section{REFERENCES}

[1] Silver, A. 2012,“Aging into exclusion and social transparency: Undocumented immigrant youth and the transition to adulthood. "Lat Stud 10.

[2] Brown T ( eds . ) 2017, “Ganguly-Scrase R. Globalised dreams, local constraints: migration and youth aspirations in an Indian regional town."Children's Geographies15(5).

[3] Paceley, M. S., Okrey-Anderson, S., \& Heumann, M.(2017) "Transgender youth in small towns: perceptions of community size, climate, and support."Journal of Youth Studies, 20(7).

[4] Zhang YW (2015) . The rise of new audiences: the new space of Chinese films. J. Contemporary films, 12:12-17.

[5] Hong ZX. (2017) Economic analysis of "small town youth" group in the new era. J. Zhifu era, 11: 71

[6] Lu DW. (2018) What's the difference between young people in big cities and "young people in small towns" in their views on home ownership? Let young people's views on home ownership be properly decoupled from class anxiety. J. People's forum, 33: 108-109

[7] Wang YL(2019). A study on the characteristics of consumption culture of young people in small towns -- starting from the field of cultural industry . J.China Youth Studies, 06: 73-78 
[8] Hamas. (1994) structural transformation of the public sphere. Trans. Cao Weidong et al. Shanghai: Xuelin publishing house. pp. 22-24.

[9] Tang YF. (2019)Reconstruction of public field, sense of community belonging and urban integration of landless farmers . J. Journal of China Agricultural University (SOCIAL SCIENCE EDITION).04: 78-85.

[10] Kaufka, Kurt.(2010) Principles of Gestalt psychology. Trans. By Li Wei. Beijing: Peking University Press. P. 200.

[11] Chen XY, Luo MK. (2020)The index and the empirical study of the willingness to share social media: Taking the voice forwarding behavior as an example, tiktok . J. intelligence exploration, 12: 5057.

[12] Qin B, Tang J. (2020)Vocational training and urban integration of floating population: Based on the analysis of comprehensive survey of rural residents in China .J. Urban development research. 12: 12-19

[13] Zhang HC, Chu PF. (2019)Internal structure of social integration of floating population in China .J. Journal of South China Normal University (SOCIAL SCIENCE EDITION). 05: 112-121 + 191

[14] Ma WH.(2018) Construction of social support network: Analysis on the realization path of urban integration of ethnic floating population.J. JOURNAL OF SOUTHWEST UNIVERSITY FOR NATIONALITIES (HUMANITIES AND SOCIAL SCIENCES).02: 55-61

[15] Zeng YB, Ye FL. (2020) Political values and social stability of the second generation of migrant workers.J. Contemporary youth studies.05: 30-36

[16] Liu YM. (2020) Research on social integration of migrant farmers .J. JOURNAL OF YUNNAN UNIVERSITY FOR NATIONALITIES (PHILOSOPHY AND SOCIAL SCIENCES).06: $118-123$

[17] Yue Z, Liang H. (2020) The effect of social capital on the health of rural elderly.J. Journal of South China Agricultural University (SOCIAL SCIENCE EDITION).06: 34-45

[18] Bai K, Wang XN. (2018) Research on the influence of social atmosphere on the local integration of tourism labor immigrants -- Taking Lijiang ancient city as an example .J. Human geography05: 133-142

[19] Xiao BY, Zhu Y, Lin LY. (2020) A study on the subjective social integration of floating population and its influencing factors based on the two-way comparison of integration isolation: a case study of fu xia quan urban agglomeration .J .Geographic research.12: 2796-2807

[20] Peng DS.(2020) Research on the urban integration of the elderly floating population under the background of family mobility .J. Journal of Shenzhen University (HUMANITIES AND SOCIAL SCIENCES EDITION).06: 105-114

[21] Ni LX, (2020) European tree and the same. The integration of socialist core values into precise Poverty Alleviation: logic, Dilemma and value realization.J. Jianghuai forum.04: 69-73

[22] Zhang an, Xue R. (2020) Research on the social adaptability of floating population in Urban Villages -- a case study of XuXi community in Taiyuan.J. Jinyang academic journal.05: 100-104

[23] Liu G, Yin JL, Liu J. (2019)70 years of Chinese corporate culture: practical development and theoreticalconstruction.J.Economic management.10: 194-208 